Research Article

\title{
Experimental Study on Steel to FRP Bonded Lap Joints in Marine Applications
}

\author{
Çiçek Özes ${ }^{1}$ and Nurhan Neșer ${ }^{2}$ \\ ${ }^{1}$ Faculty of Engineering, Dokuz Eylul University, 35397 Izmir, Turkey \\ ${ }^{2}$ Dokuz Eylul University, Graduate School of Natural and Applied Sciences, 35397 Izmir, Turkey \\ Correspondence should be addressed to Çiçek Özes; cicek.ozes@deu.edu.tr
}

Received 23 January 2015; Revised 3 July 2015; Accepted 5 July 2015

Academic Editor: Francesco Delogu

Copyright (๑) 2015 Ç. Özes and N. Neşer. This is an open access article distributed under the Creative Commons Attribution License, which permits unrestricted use, distribution, and reproduction in any medium, provided the original work is properly cited.

Steel structures coated with fiber-reinforced polymer (FRP) composites have gained wide acceptance in marine industry due to their high strength-to-weight ratio, good protection from environmental degradation, and impact loads. In this study, adhesive bonding performance of single-lap bonded joints composed of steel coated with FRP has been investigated experimentally for three different surface roughness and two epoxy types. Single-lap bonded joints have been tested under tensile loading. The adhesive bonding performance has been evaluated by calculating the strain energy values. The results reveal that the surface roughness of steel has a significant effect on the bonding performance of steel to FRP combinations and the performance of the resin can be improved by using the primer in an economical way.

\section{Introduction}

The use of composites is progressively taking place in ship industry due to their high strength-to-weight ratios and excellent corrosion resistance, lower structural weight, lower fabrication and repair cost, higher stiffness, improved damage tolerance, and fatigue performance. There are many applications for composites, including the current and potential use in hulls and decks, bulkheads, advanced mast systems, propellers, pipes, pumps, and other equipment in ship structures [1-4].

Steel ship's superstructure is coated by fiber-reinforced polymer (FRP) to improve the stability and functionality of the ship by reducing and redistributing its weight and to make the management of the ship much more cost-effective. Besides these, to protect the ship hulls from the impact loads caused by grounding and collision and from the marine environmental degradation, ship hulls are also coated with FRPs.

Composite-to-steel joints are important components in these structures due to their combined attributes of both composites and metal. Related research has been described in the literature. Hildebrand [5] investigated solutions to joints between large FRP sandwich and steel structures. Their study showed that the static strength was found to be adequate compared to the traditional joints. Wright et al. [6] researched a fibre-reinforced composite-to-steel connection for ship bulkheads. These joints were tested in tension, compression, and lateral bending. They found that symmetric rather than asymmetric joints provide better strength characteristics. The static characterization of composite-to-steel joint was investigated by $\mathrm{Li}$ et al. [7]. Their results showed that the change of geometric parameters is an effective way to reduce weight and improve performance for the composite-to-steel joints.

The strength of joints between composite and steel is one of the most important issues in ship strength. The large difference in mechanical properties (stiffness, coefficient of thermal expansion, etc.) between the adherents and the large anisotropy of FRP create difficulties: that is, the stiffness mismatch generally leads to large stress concentration and accordingly weak joints [3].

Another drawback of such a structure is its susceptibility to delamination [8-10]. As bonded joints with composite adherends are used, interlaminar failure is usually found over the failure surface. Delamination is caused by the weakness of 
the composite adherends in the through-thickness direction [11].

The term delamination is often chosen to describe the propagation of an interlaminar crack, which can undermine the flexural stiffness of a composite laminate [12]. A system's ability to resist delamination is known as toughness. A critical force or combination of forces, known as the critical crackextension force, is needed to initiate crack growth. This value is also known as the fracture toughness of a material and has been given the name fracture energy, since it gives the necessary energy for crack growth $[13,14]$.

Other typical failure modes of bonded joints are cohesive failure, which is failure within the adhesive, interfacial failure, failure along the interface between adherend and adhesive, or adherend failure. To determine the failure modes and the related performance of an adhesive bonded joint, several experimental and theoretical researches have been carried out. Zhao and Zhang [15] wrote an article dealing with the critical review and interpretation of existing research on "state-of-the-art review on FRP strengthened steel structures." It has in-depth coverage on the following aspects: the bond between steel and FRP, the strengthening of steel hollow section members, and fatigue crack propagation in the FRPsteel system. Teng et al. [16] presented another state-of-theart review on "strengthening of steel structures with fiberreinforced polymer composites." The following topics were discussed in that paper: steel surface preparation for adhesive bonding, selection of a suitable adhesive, and bond behavior between FRP and steel. Teng et al. [17] experimentally studied the effects of steel surface treatment and adhesive properties on the adhesion strength between steel and adhesive.

The durability of an adhesive joint also depends on the type of surface preparation of the adherend [18]. In literature, the treatment and characterization of steel surfaces for adhesive bonding are studied by Baldan [10] and Harris and Beevers [19]. They presented their results on the adhesion strength of a steel/adhesive interface by mechanical and chemical bonding. Grit blasting is recommended on the FRP strengthening of metallic structures by Cadei et al. [20].

This experimental study, aiming to contribute the related efforts which the industry pays a lot of importance to, has been focused on the bonding performance of two materials which have different properties: steel and FRP. The bonding performance between FRP and shipbuilding steel has been investigated by changing the surface roughness by blasting of steel and epoxy types. Tests have been carried out using single-lap joint configuration. The data obtained from the tests have been evaluated quantitatively by measuring the strain energy and comparisons of the systems performance are presented by taking into account different surface preparations and epoxy products.

\section{Strain Energy Calculation for Single-Lap Joint Tests Data}

Different analysis techniques have been suggested in order to characterize the failure of the joint, including analytical solutions and numerical methods. One of the most well-known

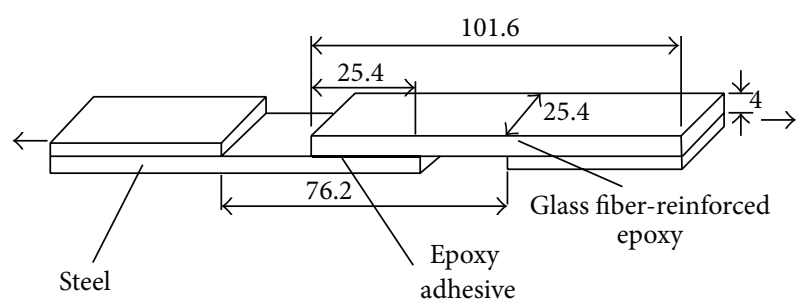

FIGURE 1: Test specimens (ASTMD5868-01).

TABle 1: Properties of the epoxies.

\begin{tabular}{lcc}
\hline & Product A & Product B \\
\hline Tensile strength $(\mathrm{MPa})$ & 60 & 50 \\
Flexural strength $(\mathrm{MPa})$ & 97 & 73 \\
Density of the mixture $\left(\mathrm{g} / \mathrm{cm}^{3}\right)$ & 1.1 & 1.1 \\
\hline
\end{tabular}

method is the average stress method which assumes that the strength of the joint is governed by the average shear along the joint at the failure load. The bending effect due to the eccentricity of the load path and deformation in the adhesive and adherents is not taken into account. The adhesive is considered to deform only in shear and the adherend to be rigid [21-24]. The average shear stress is expressed as [1]

$$
\tau=\frac{P}{b \cdot L}
$$

where $P$ is the applied load, $b$ is the joint width, and $L$ is the overlap length.

The area under the load-displacement curve has been calculated and taken into account as the performance parameter of the single-lap joints.

\section{Materials and Specimen Preparations}

The geometry and dimensions of the test specimens were prepared according to ASTMD5868-01 (standard test method for lap shear adhesion for fiber-reinforced plastic (FRP) bonding) as shown in Figure 1.

3.1. Composite Parts. Fiber-reinforced polymer composites have been laminated by hand layup method using three layers (CSM of $450 \mathrm{~g} / \mathrm{m}^{2} /$ Woven of $400 \mathrm{~g} / \mathrm{m}^{2} / \mathrm{CSM}$ of $450 \mathrm{~g} / \mathrm{m}^{2}$ ) of E-glass.

Two different epoxy products have been used as parameter that affects the bonding performance. The properties of these given by producers are shown in Table 1.

Product $\mathrm{A}$ is the universal type epoxy-based adhesive. Product B is the solvent free epoxy-based lamination.

3.2. Steel Plate. The A grade steel of a thickness of $4 \mathrm{~mm}$ was coded as St37 with a quality assurance number of 3701 . The material properties are given in Table 2. The dimensions of the specimen were $25 \mathrm{~mm}$ of width and $125 \mathrm{~mm}$ of length. At the end of the preparation stage, the edges of the steel specimens have been grinded. 
TABLE 2: Chemical and physical properties of the A grade shipbuilding steel.

\begin{tabular}{|c|c|c|c|c|c|c|c|c|c|}
\hline \multicolumn{10}{|c|}{ Chemical composition (\%) } \\
\hline $\begin{array}{l}\text { C } \\
(\max )\end{array}$ & $\begin{array}{c}\mathrm{Mn} \\
(\mathrm{min})\end{array}$ & $\begin{array}{c}\mathrm{P} \\
(\max )\end{array}$ & $\begin{array}{c}S \\
(\max )\end{array}$ & $\begin{array}{c}\mathrm{Si} \\
(\max )\end{array}$ & $\begin{array}{c}\mathrm{Al} \\
(\mathrm{min})\end{array}$ & $\begin{array}{c}\mathrm{Ni} \\
(\max )\end{array}$ & $\begin{array}{c}\mathrm{Cr} \\
(\max )\end{array}$ & $\begin{array}{c}\text { Mo } \\
(\max )\end{array}$ & $\begin{array}{c}\mathrm{Cu} \\
(\max )\end{array}$ \\
\hline 0.18 & 0.60 & 0.025 & 0.020 & 0.40 & 0.020 & 0.15 & 0.10 & 0.05 & 0.15 \\
\hline \multicolumn{3}{|c|}{ Yield strength $(\mathrm{MPa})$} & \multicolumn{3}{|c|}{ Tensile strength $(\mathrm{MPa})$} & \multicolumn{4}{|c|}{ Minimum elongation $\left(L_{0}=200 \mathrm{~mm}\right)$} \\
\hline \multicolumn{3}{|c|}{235} & \multicolumn{3}{|c|}{$400-520$} & \multicolumn{4}{|c|}{21} \\
\hline
\end{tabular}

3.2.1. Surface Preparation of Steel Plate. Surface preparation is a necessary pretreatment, to improve bond strength and durable adhesive joint between different substrates [25]. Firstly, the surface is cleaned using a solvent or another chemical and to increase the contact surface it is cleaned by blasting. A material known as priming is applied to the surface in order to improve the wetting and to protect the surface from oxidation after cleaning.

Grades of blasting have been established by the International Standard Organization ISO8501-1 (preparation of steel substrates before application of paints and related products):

Sal: light blast cleaning: blast cleaning of all except tightly adhering residues of mill scale, rust, and coatings, exposing numerous evenly distributed flecks of underlying metal.

Sa2: thorough blast cleaning: blast cleaning until at least two-thirds of the surface is free of all visible residues.

Sa2.5: very thorough blast cleaning: blast cleaning until at least $95 \%$ of the surface area is free of all visible residues.

Sa3: blast cleaning to visually clean steel white metal: blast removal of all visible rust, mill scale, paint, and foreign matter.

In this study, steel test specimens have been prepared in three different surface conditions to determine the effect of the sand blasting: untreated surface, light blast cleaning (Sa1), and very thorough blast cleaning (Sa2.5).

To compare the surface roughness values, Keane-Tator brand (1976) surface profile comparator has been used [26].

Before the lamination process, steel surfaces have been coated by primer to improve wetting and to protect the surface from oxidation after cleaning. According to the producers' instructions, the specimens having untreated surface were coated with an epoxy-based primer known as the "surface tolerant primer." The specimens having Sal and Sa2.5 surface roughness were coated with zinc epoxy-based primer. Properties of the epoxy primer used on surfaces are given in Table 3 [27].

\section{Experimental Procedure}

Single-lap joint specimens have been tested under tensile loading using the Shimadzu AUTOGRAPH AG-IS test machine at room temperature in displacement control. The specimens were mounted in hydraulic grips. During
TABle 3: Properties of the epoxy primer.

\begin{tabular}{|c|c|c|}
\hline & $\begin{array}{l}\text { Surface tolerant } \\
\text { epoxy primer }\end{array}$ & $\begin{array}{c}\text { Zinc } \\
\text { epoxy-based } \\
\text { primer } \\
\end{array}$ \\
\hline Colour & Grey, red & Grey \\
\hline Finish, dry film & Semi-Matt & Matt \\
\hline Volume solids (\%) & $79( \pm 1)$ & $75( \pm 1)$ \\
\hline $\begin{array}{l}\text { Specific gravity } \\
\left(\mathrm{gr} / \mathrm{cm}^{3}\right)\end{array}$ & $1.47( \pm 0.05)$ & $2( \pm 0.05)$ \\
\hline $\begin{array}{l}\text { Recommended DFT } \\
\text { (dry film thickness) } \\
\text { range }(\mu)\end{array}$ & 100 & $50-70$ \\
\hline $\begin{array}{l}\text { Recommended WFT } \\
\text { (wet film thickness) } \\
\text { range }(\mu)\end{array}$ & 150 & 70 \\
\hline
\end{tabular}

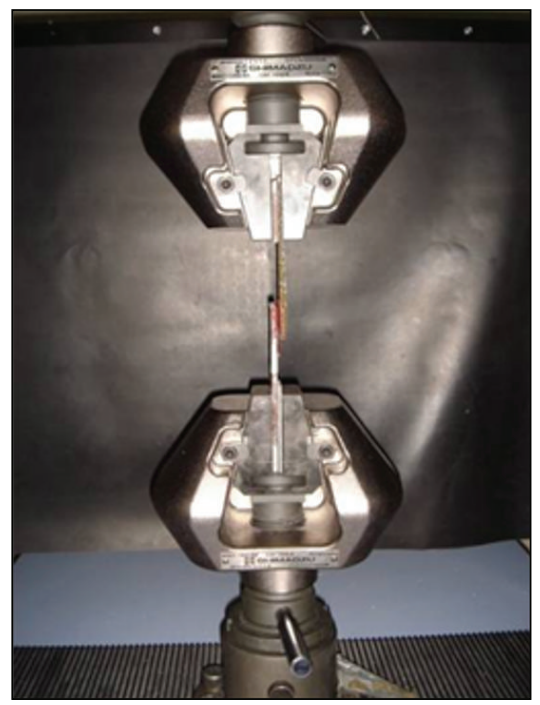

Figure 2: Test fixtures.

the test, the specimens were pulled apart by a tensile testing machine at a constant displacement rate of $1.2 \mathrm{~mm} / \mathrm{min}$ selected according to the ASTM D5868 (lap shear adhesion test for FRP).

A high-resolution CCD camera was used to observe the deformation and the crack initiation and propagation. The test fixtures are shown in Figure 2.

The area under the load-displacement curve has been calculated and taken into account as the performance parameter of the single-lap joints. 
TABLE 4: Maximum load and displacement values in shear loading condition.

\begin{tabular}{|c|c|c|c|c|c|c|}
\hline & SOEA & SOEB & SalEA & SalEB & Sa2.5EA & Sa2.5EB \\
\hline Maximum load, $P(\mathrm{~N})$ & 2438.943 & 6823.063 & 3965.394 & 7767.757 & 4984.029 & 7038.196 \\
\hline Maximum displacement, $\delta(\mathrm{mm})$ & 1.999 & 2.899 & 2.119 & 3.499 & 2.139 & 3.079 \\
\hline
\end{tabular}
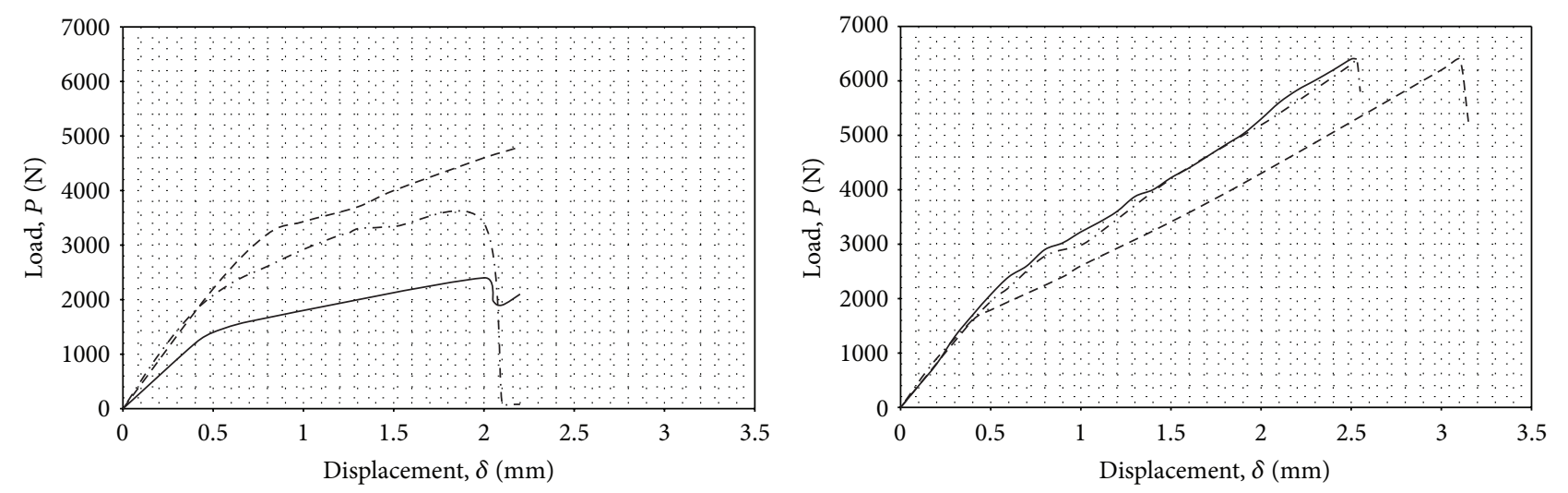

$\begin{array}{ll}- & \text { SOEA } \\ - & \text { Sa1EA } \\ --- & \text { Sa2.5EA }\end{array}$

$$
\begin{aligned}
& \text { — S0EB } \\
& \text {-.- Sa1EB } \\
& \text { - - Sa2.5EB }
\end{aligned}
$$

Figure 3: Load-displacement curves sample for single-lap joint tensile tests.

\section{Results and Discussions}

The specimens having surface roughness were coded as SaEb. In this coding system "Sa" stands for grades of blasting, while $E$ stands for epoxies and $b$ is for the type of the related product (A or B). In this study, untreated, light blast cleaning and very thorough blast cleaning surfaces were coded as S0Eb, SalEb, and $\mathrm{Sa} 2.5 \mathrm{~Eb}$, respectively.

There are six cases; six tests were performed for each case. In Table 4 , the relation between maximum loads and displacements has been given in some selected individual tests.

From Table 4, it can be seen that as the surface roughness of steel parts increases, the load level also increases. That means that the highest surface roughness is the highest joint performance. This conclusion is also valid for each epoxy product. However, joints with epoxy A product have failed in a load level lower than those of joints with epoxy B. For the same surface roughness conditions, there is a difference between the maximum loads for each type of product. This difference is maximal for untreated surfaces. This phenomenon can be explained by the effect of "surface tolerant primer, which the producer of epoxy A recommends for unprepared surfaces." Maximum displacements in the specimens containing epoxy B are much higher than those of the specimens manufactured with epoxy A.

An example of the load-deformation curve recorded during the tests is shown in Figure 3. Curves in all conditions are continuous having a smooth character. The specimen containing epoxy B needs very high loads to fail compared with the specimens with epoxy A. Failure caused by shear loads occurs almost at the same displacement for the samples containing epoxy type A.

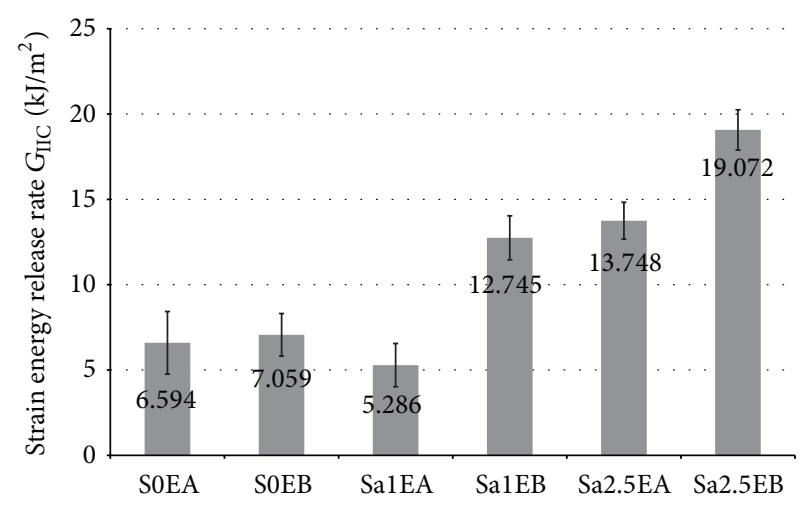

FIGURE 4: Average value of strain energies with \pm 1 standard deviation.

Average values of strain energies are presented in Figure 4 and minimum and maximum values are presented in Table 5. The samples which have the codes of S0 represent the steel materials which have the surfaces that are not treated in any way. This means that these samples are at the conditions as they were purchased from the related market. Before joining, surface tolerant primer has been applied to this kind of samples. Results show that surface tolerant primer has a positive effect on the joining performance to a certain extent. While S0EA has superior performance compared to SalEA, Sa2.5EA is much stronger than S0EA. During the design and production stages of a structure, to minimize the cost and duration of production it is highly advisable to consider the application of surface tolerant primer. 
TABLE 5: Minimum and maximum values of strain energies.

\begin{tabular}{lcccccc}
\hline & S0EA & S0EB & Sa1EA & Sa1EB & Sa2.5EA & Sa2.5EB \\
\hline $\begin{array}{l}\text { Maximum } \\
{\left[\mathrm{kJ} / \mathrm{m}^{2}\right]}\end{array}$ & 9.248 & 8.307 & 7.089 & 14.389 & 14.895 & 21.502 \\
$\begin{array}{l}\text { Minimum } \\
{\left[\mathrm{kJ} / \mathrm{m}^{2}\right]}\end{array}$ & 4.515 & 5.350 & 4.038 & 11.447 & 12.507 & 18.651 \\
$\begin{array}{l} \pm 1 \text { standard } \\
\text { deviation }\end{array}$ & 1.838 & 1.250 & 1.270 & 1.288 & 1.080 & 1.180 \\
\hline
\end{tabular}

Taking into consideration the energy calculations, the difference between the products performance can be evaluated clearly. The specimens containing epoxy B show higher performance. Surface preparation as well as using primer has significant effect on the joint performance. Epoxy A was slightly weaker than epoxy B for this type of loading. Sand blasting and priming improve the performance of the adhesive bonding.

\section{Conclusions}

To determine the reliability of bonding of steel and FRP, it is necessary to study the failure mechanism on the interface of the related materials. Considering this very critical failure for laminated materials, FRP composites and shipbuilding steel bonding's performance have been measured under single-lap joints tensile loading condition as the case study.

Strain energy release rates for single-lap tests, as the measures of the performance, have been calculated for three roughness values of steel surface and for two epoxy products of different producers.

From the test results and the calculations, the following has been concluded:

(i) The surface roughness of steel has a significant effect on the bonding performance between the fiberreinforced polymer (FRP) composites and the steel.

(ii) These tests can be used as quality assurance tools for epoxy products. To maximize the effectiveness of FRP strengthening, the selection of an appropriate adhesive is very important.

(iii) The performance of the resin can be improved by using the primer in an economical way.

(iv) The types of epoxy play a key role in determining the load-carrying capacity between the glass fiberreinforced polymer (FRP) composites and the shipbuilding steel.

\section{Conflict of Interests}

The authors declare that there is no conflict of interests regarding the publication of this paper.

\section{Acknowledgments}

The authors would like to acknowledge the epoxy producers for providing materials and the people of Laboratory of
Applied Mechanics Personnel of Dokuz Eylul University Engineering Faculty, Mechanical Engineering Department, for their invaluable assistance and advices.

\section{References}

[1] S. W. Boyd, J. I. R. Blake, R. A. Shenoi, and J. Mawella, "Optimisation of steel-composite connections for structural marine applications," Composites Part B: Engineering, vol. 39, no. 5, pp. 891-906, 2008.

[2] J. Cao, Fiber reinforced composites/steel hybrid ship structures [Ph.D. thesis], Lehigh University, 2005.

[3] J. Cao and J. L. Grenestedt, "Design and testing of joints for composite sandwich/steel hybrid ship hulls," Composites Part A: Applied Science and Manufacturing, vol. 35, no. 9, pp. 1091-1105, 2004.

[4] A. P. Mouritz, E. Gellert, P. Burchill, and K. Challis, "Review of advanced composite structures for naval ships and submarines," Composite Structures, vol. 53, no. 1, pp. 21-24, 2001.

[5] M. Hildebrand, "Efficient solutions for joints between large FRP-sandwich and metal structures," in Proceedings of the 19th SAMPE Europe International Conference, pp. 417-428, Paris, France, 1998.

[6] P. N. H. Wright, Y. Wu, and A. G. Gibson, "Fibre reinforced composite-steel connections for transverse ship bulkheads," Composites: Part A, vol. 29, no. 10, pp. 549-557, 2000.

[7] X. W. Li, P. Li, Z. Lin, and D. M. Yang, "Analysis and optimization of composite to steel joints for ships," Sensors \& Transducers, vol. 182, no. 11, pp. 10-16, 2014.

[8] M. D. Banea and L. F. M. da Silva, "Adhesively bonded joints in composite materials: an overview," Proceedings of the Institution of Mechanical Engineers, Part L: Journal of Materials: Design and Applications, vol. 223, no. 1, pp. 1-18, 2009.

[9] R. A. Flinn and P. K. Trojan, Engineering Materials and Their Applications, John Wiley \& Sons, Hoboken, NJ, USA, 4th edition, 1995.

[10] A. Baldan, "Adhesively-bonded joints and repairs in metallic alloys, polymers and composite materials: adhesives, adhesion theories and surface pretreatment," Journal of Materials Science, vol. 39, no. 1, pp. 1-49, 2004.

[11] K.-H. Nguyen, J.-H. Kweon, and J.-H. Choi, "Failure load prediction by damage zone method for single-lap bonded joints of carbon composite and aluminum," Journal of Composite Materials, vol. 43, no. 25, pp. 3031-3056, 2009.

[12] T. Bullions, R. Mehta, B. Tan, J. McGrath, D. Kranbuehl, and A. Loos, "Mode I and Mode II fracture toughness of highperformance 3000 gmole $^{-1}$ reactive poly(etherimide)/carbon fiber composites," Composites Part A: Applied Science and Manufacturing, vol. 30, no. 2, pp. 153-162, 1999.

[13] G. E. Dieter, Mechanical Metallurgy, McGraw-Hill, New York, NY, USA, 1986.

[14] M. D. Rakestraw, M. Vrana, T. Chang, D. Dillard, T. C. Ward, and J. G. Dillard, "Evaluation of adhesive performance using static, fatigue, and environmental fracture testing," Tech. Rep. CASS/MESc/94-2, Center for Adhesive and Sealant Science, Virginia Polytechnic Institute and State, Blacksburg, Va, USA, 1994.

[15] X.-L. Zhao and L. Zhang, "State-of-the-art review on FRP strengthened steel structures," Engineering Structures, vol. 29, no. 8, pp. 1808-1823, 2007. 
[16] J. G. Teng, T. Yu, and D. Fernando, "Strengthening of steel structures with fiber-reinforced polymer composites," Journal of Constructional Steel Research, vol. 78, pp. 131-143, 2012.

[17] J. G. Teng, D. Fernando, T. Yu, and X. L. Zhao, "Treatment of steel surfaces for effective adhesive bonding," in Proceedings of the 5th International Conference on FRP Composites in Civil Engineering (CICE '10), pp. 865-868, Beijing, China, September 2010.

[18] E. Jarry and R. A. Shenoi, "Performance of butt strap joints for marine applications," International Journal of Adhesion \& Adhesives, vol. 26, no. 3, pp. 162-176, 2006.

[19] A. F. Harris and A. Beevers, "Effects of grit-blasting on surface properties for adhesion," International Journal of Adhesion \& Adhesives, vol. 19, no. 6, pp. 445-452, 1999.

[20] J. M. C. Cadei, T. J. Stratford, L. C. Hollaway, and W. G. Duckett, Strengthening Metallic Structures Using Externally Bonded FibreReinforced Polymers, C595, CIRIA, London, UK, 2004.

[21] M. S. Kafkalidis and M. D. Thouless, "The effects of geometry and material properties on the fracture of single lap-shear joints," International Journal of Solids and Structures, vol. 39, no. 17, pp. 4367-4383, 2002.

[22] J. A. Harris and R. A. Adams, "Strength prediction of bonded single lap joints by non-linear finite element methods," International Journal of Adhesion and Adhesives, vol. 4, no. 2, pp. 65-78, 1984.

[23] D. A. Bigwood and A. D. Crocombe, "Non-linear adhesive bonded joint design analyses," International Journal of Adhesion and Adhesives, vol. 10, no. 1, pp. 31-41, 1990.

[24] A. D. Crocombe and D. A. Bigwood, "Development of a full elasto-plastic adhesive joint design analysis," Journal of Strain Analysis for Engineering Design, vol. 27, no. 4, pp. 211-218, 1992.

[25] S. Ebnesajjad and C. F. Ebnesajjad, Surface Treatment of Materials for Adhesion Bonding, William Andrew Inc, Applied Science Publishers, 2006.

[26] KTA-Tator, Keane-Tator Surface Profile Comparator for Shot Blast Cleaned Surfaces, KTA-Tator, Pittsburgh, Pa, USA, 1976.

[27] Barva Organic Chemicals, http://www.best-maritime.info/ index.php/l/en/mod/vc_contact/company_id/80661/sb/3. 

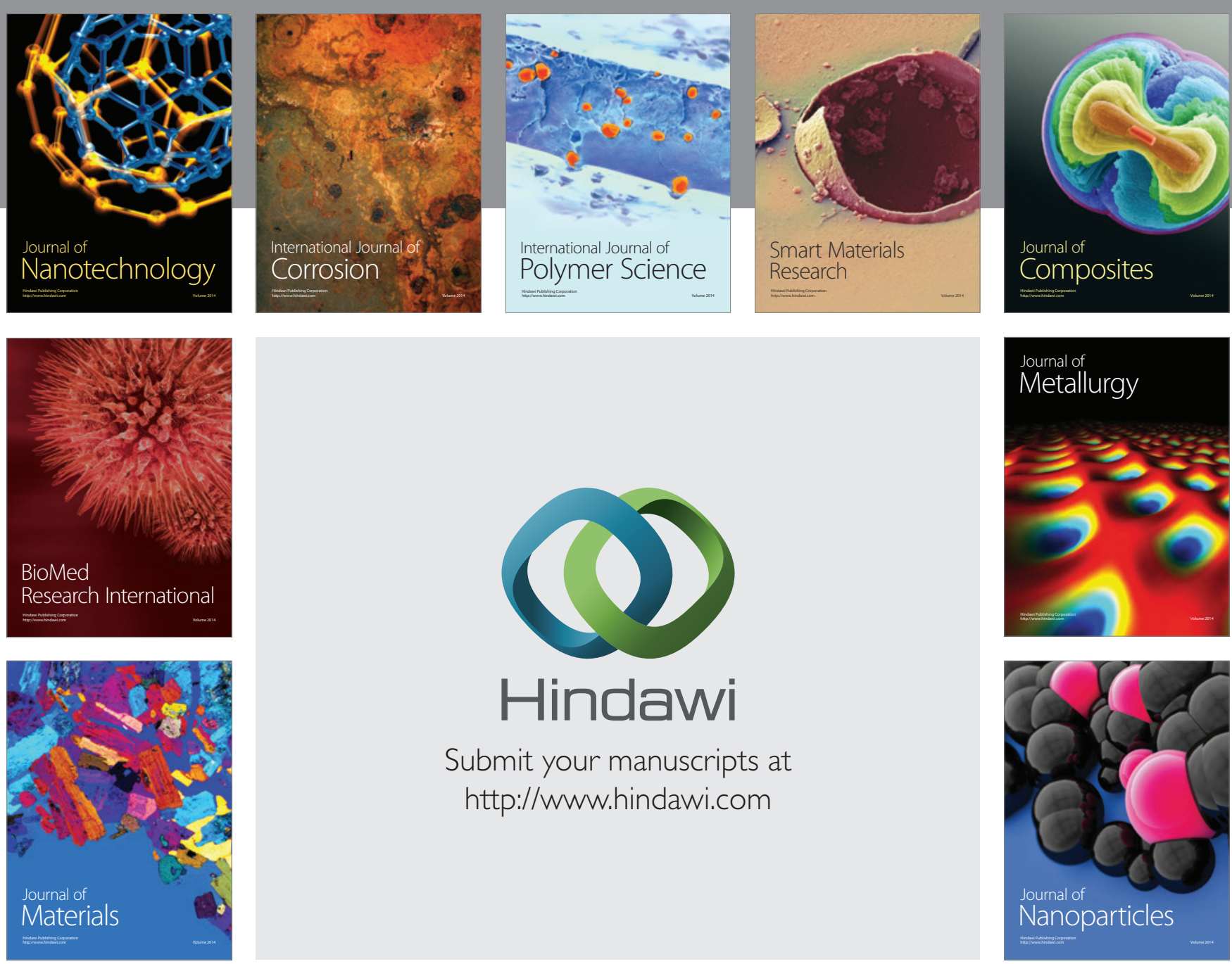

Submit your manuscripts at http://www.hindawi.com
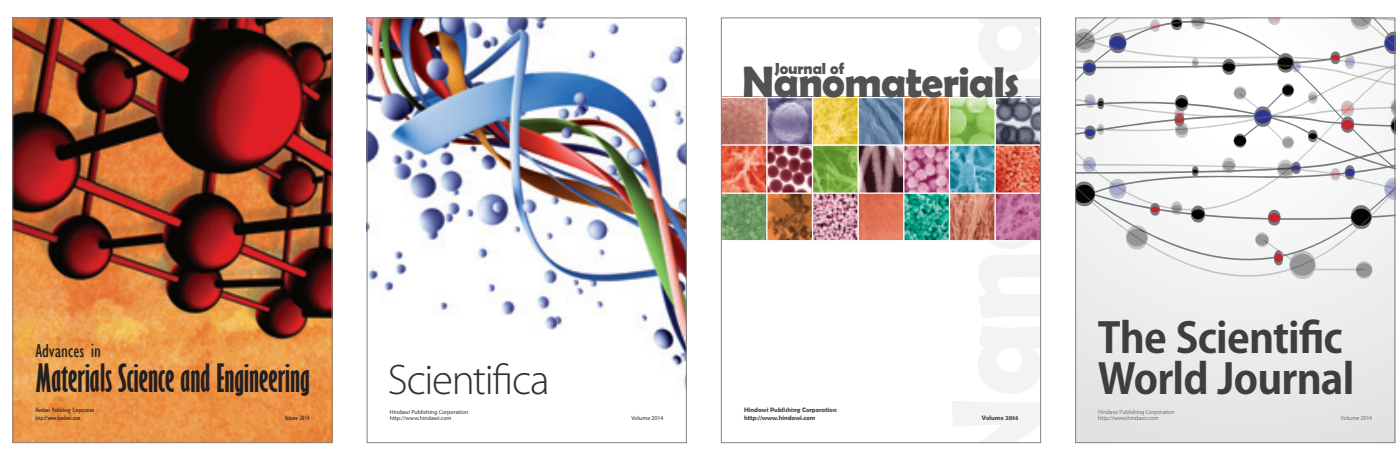

\section{The Scientific World Journal}
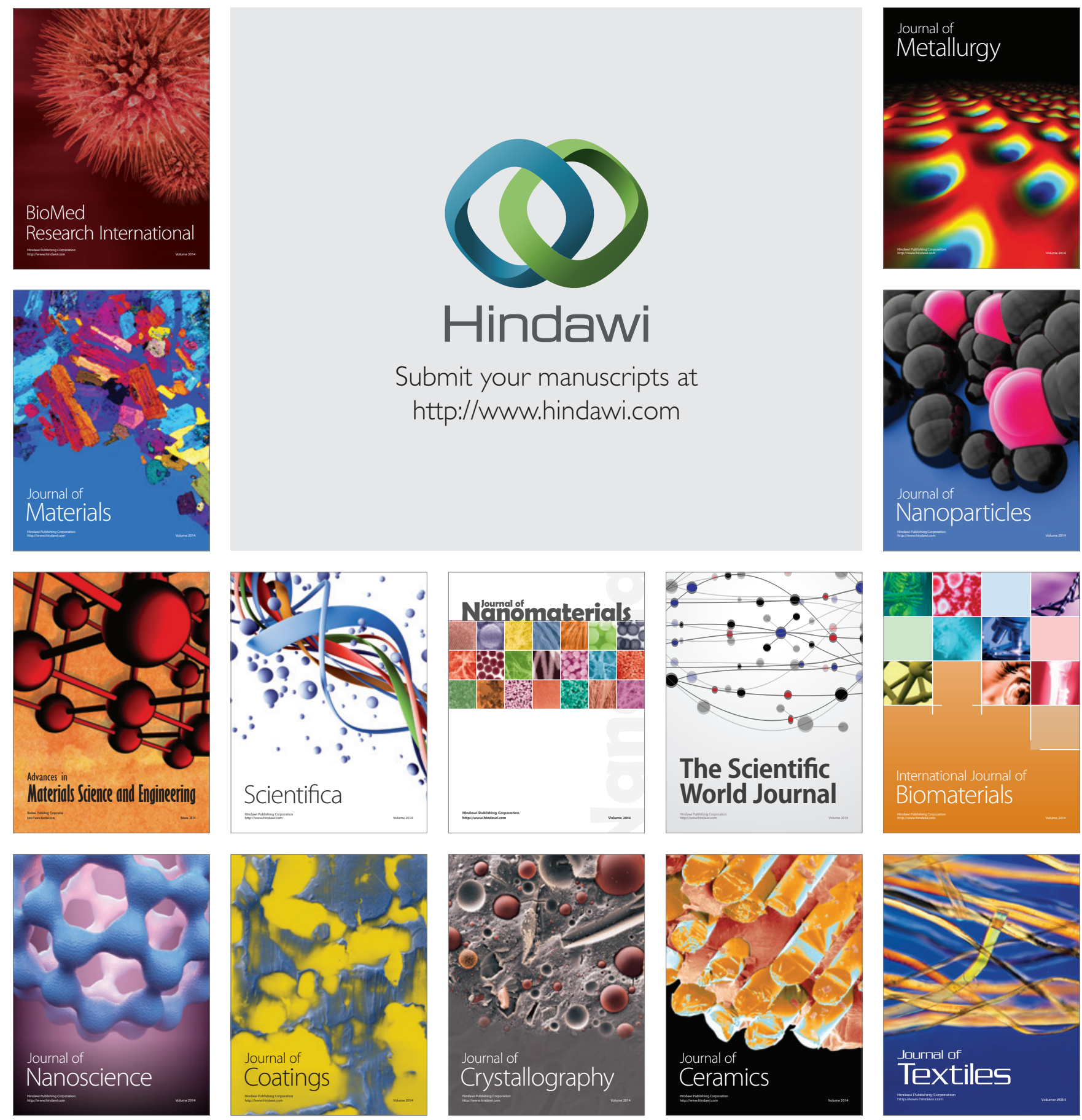